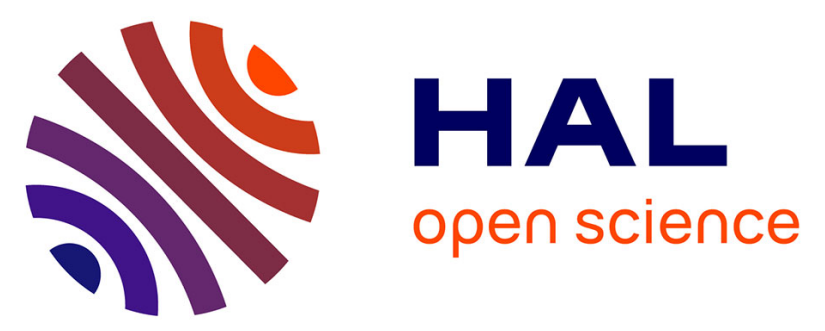

\title{
The halophytic model plant Thellungiella salsuginea exhibited increased tolerance to phenanthrene-induced stress in comparison with the glycophitic one Arabidopsis thaliana: Application for phytoremediation
}

Moez Shiri, Mokded Rabhi, Chedly Abdelly, Abdelhak El Amrani

\section{To cite this version:}

Moez Shiri, Mokded Rabhi, Chedly Abdelly, Abdelhak El Amrani. The halophytic model plant Thellungiella salsuginea exhibited increased tolerance to phenanthrene-induced stress in comparison with the glycophitic one Arabidopsis thaliana: Application for phytoremediation. Ecological Engineering, 2015, 74, pp.125-134. 10.1016/j.ecoleng.2014.09.123 . hal-01096907

\section{HAL Id: hal-01096907}

https://hal-univ-rennes1.archives-ouvertes.fr/hal-01096907

Submitted on 22 May 2015

HAL is a multi-disciplinary open access archive for the deposit and dissemination of scientific research documents, whether they are published or not. The documents may come from teaching and research institutions in France or abroad, or from public or private research centers.
L'archive ouverte pluridisciplinaire HAL, est destinée au dépôt et à la diffusion de documents scientifiques de niveau recherche, publiés ou non, émanant des établissements d'enseignement et de recherche français ou étrangers, des laboratoires publics ou privés. 
Title: The halophytic model plant Thellungiella salsuginea exhibited increased tolerance to phenanthrene-induced stress in comparison with the glycophitic one Arabidopsis thaliana: Application for phytoremediation

\section{Authors' names:}

Moez Shiri ${ }^{\mathrm{a}, \mathrm{b}^{*}}$, Mokded Rabhi $^{\mathrm{b}}$, Chedly Abdelly ${ }^{\mathrm{b}}$, and Abdelhak El Amrani ${ }^{\mathrm{a}}$

\section{Authors' affiliations:}

a: Université de Rennes 1, CNRS/OSUR-UMR 6553, Ecosystèmes-BiodiversitéEvolution, Campus de Beaulieu, Bâtiment 14A, 35042 Rennes cedex, France.

b. Laboratory of Extremophile Plants, Centre of Biotechnology of Borj Cedria, P.O. Box 901, 2050 Hammam-Lif, Tunisia.

${ }^{*}$ Corresponding author: Moez Shiri

E-mail: moise.shiri@yahoo.fr

Phone number: (+ 33)2.23.23.51.24

Fax number: (+ 33)2.23.23.50.26 


\section{Abstract}

Polycyclic aromatic hydrocarbons constitute a large family of organic environmental pollutants. Hence, a particular attention has been attributed to all approaches involved in the reduction of their contamination in water and natural ecosystems. Plant tolerance, absorption, accumulation, and likely biodegradation of these pollutants, known as phytoremediation, have emerged as an efficient technique to remediate environments contaminated with polycyclic aromatic hydrocarbons. The present work was aimed to compare the tolerance to phenanthrene (a polycyclic aromatic hydrocarbon) in the two model plants: Arabidopsis thaliana (glycophyte) and Thellungiella salsuginea (halophyte). Our study showed that the development of these two species was reduced under phenanthrene stress, the effect being more pronounced in Arabidopsis thaliana than in Thellungiella salsuginea. In parallel, results from the intrinsic quantum yield of photosystem II and chlorophyll concentrations were concomitant with those of growth and phenotypic changes, and confirmed the higher tolerance of Thellungiella salsuginea compared to that of Arabidopsis thaliana. The intrinsic quantum yield of photosystem II was drastically decreased in the glycophyte, which indicates a marked disturbance in photosystem II performance. This induced a severe oxidative stress as shown by the utilization of specific reactive oxygen species probes. In parallel, the activities of glutathione reductase, gaiacol peroxidase, and superoxide dismutase were increased by 95, 73, and 36\%, respectively, which indicates a marked phenanthrene-induced oxidative stress. In Thellungiella salsuginea, photosystem II performance was not significantly affected. This species showed less accumulated reactive oxygen species than Arabidopsis thaliana. Its enzymatic antioxidant system showed few changes as superoxide dismutase was the only enzyme whose activity was enhanced $(+34 \%)$. A 
much higher capacity of recovery was also noticed in this halophyte as compared to the glycophyte. Indeed, it seems that Thellungiella salsuginea accumulated phenanthrene in stomata, which suggests its possible volatilization. All these data, taken together, add new insight to the mechanisms involved in halophytic plant tolerance to abiotic stresses and their potential use in phytoremediation.

\section{Graphical abstract}

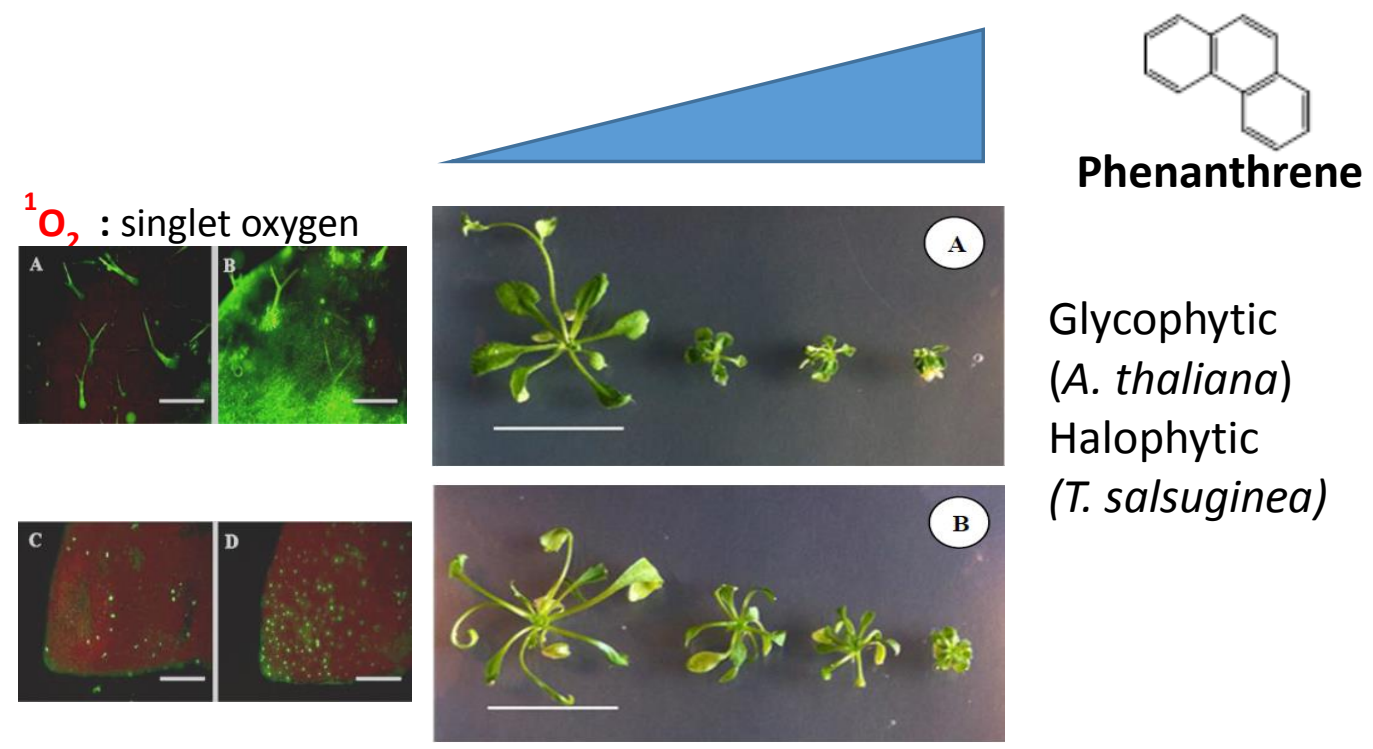

Phytoremediation of PAHs by halophytic plants 
Keywords: antioxidant enzymes, phytoremediation, phytovolatilization, photosystem II performance, polycyclic aromatic hydrocarbons.

\section{Glossary:}

${ }^{1} \mathbf{O}_{2}$ : Singlet oxygen

Car: carotenoids

CAT: Catalase

Chla: Chlorophyll $a$

Chlb: Chlorophyll $b$

DAB: 3,3'diaminobenzidine

EDTA: Ethylenediaminetetraacetic Acid

Fo: Minimal Fluorescence

$\mathbf{F}_{\mathbf{m}}$ : Maximal Fluorescence

$\mathbf{F}_{\mathbf{v}} / \mathbf{F}_{\mathbf{m}}$ : Maximal quantum efficiency of PSII photochemistry

Fv: Variable Fluorescence

FW: Fresh Weights

GPX: Gaiacol Peroxidase

GR: Glutathione Reductase

GSSG: Oxidized Glutathione

GST: Glutathione-s-transferase

$\mathbf{H}_{2} \mathrm{O}_{2}$ : Hydrogen peroxide

MDA: Malondialdehyde

MS: Murashige and Skoog

NADPH: Reduced Nicotinamide Adenine Dinucleotide Phosphate

NBT: Nitroblue Tetrazolium

$\mathbf{O}_{2} \cdots$ : Superoxide anion

PAHs: Polycyclic Aromatic Hydrocarbons

POD: Peroxidase

PSII: Photosystem II

PVPP: Polyvinyl Pyrrolidone phosphate

ROS: Reactive Oxygen Species 
SOD: Superoxide Dismutase

SOSG: Singlet Oxygen Sensor Green 


\section{Introduction}

Polycyclic aromatic hydrocarbons (PAHs) form a large family of persistent hydrophobic environmental pollutants. They are originated from the incomplete carbon combustion and they have natural (e.g., forest fires and volcano eruption) and anthropogenic (by-products in petroleum-based manufacturing) sources. They are present in coal tar, asphalt, tires, and other oil-containing products (Harvey, 1991). Their hydrophobicity and the two or more benzene rings they contain make them highly persistent in the environment (Posada-Baquero and Ortega-Calvo, 2011), very obstreperous, and difficultly degraded (Liu et al., 2009). In 2011, the Agency for Toxic Substances and Disease Registry (ATSDR, USA) ranked PAHs number 9 on the priority list of hazardous substances for the Comprehensive Environmental Response, Compensation, and Liability Act (CERCLA) with respect of their frequency, toxicity, human exposure and need of decontamination (See http://www.atsdr.cdc.gov/spl/resources/index.html). Sixteen of the most prevalent PAHs thereby were classified as Priority Pollutants (Seo et al, 2009) by the United States Environmental Protection Agency (USEPA) (Wilson and Jones, 1993). PAHs have many effects on humans and animals like DNA mutation, cancer, reactive oxygen species (ROS) generation, and cell death (Burritt, 2008; Li et al 2014; Das et al, 2014). They are classified as organic carcinogenic pollutants (Liu et al., 2009). In plants, they cause oxidative stress with a high level of generation of Reactive Oxygen Species (ROS), cell death, and necrosis (Burritt, 2008; Paskova et al., 2006). They affect growth by reducing photosynthesis activity, transpiration rate, and nutrient uptake (Liu et al., 2009; Marwood et al., 2001; Redondo-Gómez et al., 2011; Witting et al., 2003). 
All these detrimental effects of PAHs make them of high priority for remediation efforts (Liu et al., 2009). There are many techniques to clean up PAH-contaminated soils, but they are very expensive and disturb the environment if they need a transfer of pollutants to another site for treatment (Gan et al., 2009). Interestingly, the emerging, low-cost, and environment-friendly green technology phytoremediation is beginning to be used for the decontamination of soils, waters, and sediments (Vangronsveld et al., 2009). According to Kathi and Khan (2011), organic compounds are subjected to several processes in phytoremediation. They can be 1) taken up from the contaminated substratum (soil or water), 2) accumulated or processed through lignification, volatilization, metabolization, or mineralization, or 3) broken down, if they are complex molecules, into simpler molecules by plant enzymes or microbial/fungal activity. These authors cited 5 basic phytoremediation techniques: 1) Rhizofiltration, a water phytoremediation technique based on contaminant uptake by plant roots, 2) Phytoextraction, a soil phytoremediation technique involving contaminant uptake from soil. 3) Phytotransformation, a soil and water technique that involves contaminant degradation via plant metabolism 4) Phyto-stimulation, a plant-assisted bioremediation of water and soil based on the stimulation of microbial biodegradation at the root zone. 5) Phytostabilization, a phytoremediation technique that consists in the reduction of contaminant mobility and migration potential in soil. The phytoremediation of PAHs requires plant capacity to tolerate oxidant stress and to metabolize and compartmentalize PAHs in its cells and tissues (Bhargava et al., 2012; Cheema et al., 2010; Shim et al., 2012).

Responses of glycophytes to PAHs were well studied and most of them showed significant sensitivity to these constraints (Liu et al., 2009; Muratova et al., 2009; Song 
et al., 2005; Weisman et al., 2010). In this context, several investigations were performed on the model plant Arabidopsis thaliana for a better understanding of the mechanisms involved in PAH tolerance with the aim to identify selection criteria or useful tools in phytoremediation and/or amelioration programs thanks to its high intraspecific diversity and to the abundance of its developed molecular tools. The responses of this glycophyte to PAHs were studied at the physiological and morphological levels (Alkio et al., 2005) as well as at the transcriptional one (Weisman et al., 2010). Although Arabidopsis thaliana is sensitive to PAHs, it was shown to be a model plant for the understanding of phytoremediation process. However, this criterion is not sufficient as phytoremediation of a PAH-polluted site requires species showing, among other criteria, a high tolerance to PAH stress and to the PAH-induced oxidant stress (Batish et al., 2006; Herbinger et al. 2002; Selote et al., 2004). Indeed, ROS production and subsequent oxidative damage may be an important mechanism of toxicity in plants exposed to xenobiotics (Livingstone, 2001). To limit damage caused by ROS, plant cells produce antioxidant enzymes (e.g. superoxide dismutase (SOD), catalase (CAT), peroxidase (POD), and glutathione-s-transferase (GST)) as well as nonenzymatic antioxidants (e.g. glutathione and ascorbate). They represent molecular bioindicators for contaminant-mediated oxidative stress (Shao et al., 2002).

Extremophile plants may constitute interesting candidates since they have evolved, over millions of years, efficient ways to survive and sustain growth in challenging environments, which makes their study a potential source of insights for the elucidation of the mechanisms involved in their stress tolerance (Amtmann, 2009). Ben Hamed et al. (2013) reported that halophytes (a group of extremophile plants that tolerate severe salinity), especially the model plant Thellungiella salsuginea, anticipated stresses with 
high levels of antioxidants and higher defense responses to abiotic stresses compared to Arabidopsis thaliana. Halophytes have been suggested by several studies to substitute salt-sensitive crop plants commonly chosen for purposes of heavy metal phytoremediation (Manousaki and Kalogerakis, 2011). By contrast, data about halophyte adaptations to PAHs are scarce and there are only few works dealing with the use of halophytes in PAH phytoremediation (Howes and Ungar, 2002; El-Bakatoushi; 2011; Redondo-Gómez et al., 2011; Youssef, 2002). Hence a comparative study of Arabidopsis thaliana and Thellungiella salsuginea responses to PAHs and their induced oxidant stress is a valuable tool to elucidate mechanisms involved in the tolerance of excess pollutant within plant tissues. For this reason, we studied in the present work some morpho-physiological and antioxidant responses of these two plants to phenanthrene with the aim to check whether halophytes are more suitable for PAH phytoremediation than glycophytes.

\section{Material and methods}

\subsection{Plant material and growth conditions}

Seeds of Arabidopsis thaliana (Columbia-0) and Thellungiella salsuginea (Shandong wild-type) were surface-sterilized with a solution containing bayrochlore/ethanol (1/1, $\mathrm{v} / \mathrm{v}$ ) for $10 \mathrm{~min}$, rinsed in absolute ethanol, then dried overnight. Seed germination and plant growth were performed in square Petri dishes under axenic conditions. Stratification at $4{ }^{\circ} \mathrm{C}$ for 10 days was needed to enhance germination rate and frequency and young seedling growth particularly for Thellungiella salsuginea. Thereafter, seedlings were transferred into a growth chamber under controlled conditions (temperature: $22^{\circ} \mathrm{C} / 17^{\circ} \mathrm{C}$, light period: $16 \mathrm{~h}$, PAR: $85 \mu \mathrm{mol} \mathrm{m}{ }^{-2} \mathrm{~s}^{-1}$ ). Growth medium consisted of $2 \%$ sucrose, $0.8 \%(\mathrm{w} / \mathrm{v})$ agar in Murashige and Skoog (MS) basal salt mix 
(M5519, Sigma-Aldrich) adjusted to $\mathrm{pH}$ 5.7. Plantlets were then grown vertically for 3 weeks on fresh MS/2 agar medium containing: $0 \mu \mathrm{M}$ (control), 25, 50, or $100 \mu \mathrm{M}$ phenathrene dissolved in ethanol. After 21 days of treatment, plants were analyzed before or after harvest according to the considered parameter. Control plants were grown under identical conditions in the presence of the same volume of ethanol as treated plants.

\subsection{Plant harvest and recovery experiment}

At the harvest, plants of the two species were cut into shoots (rosette leaves) and roots. Samples were weighed for growth measurements. A recovery experiment was also realized for both species. Plants were subjected to $100 \mu \mathrm{M}$ phenanthrene for 2 weeks then transferred onto a control medium and grown for 4 additional weeks. Thereafter, they were harvested and their fresh weights $(\mathrm{FW})$ were determined.

\subsection{Pigment analysis}

For pigment analysis, previously-weighed rosette leaves were incubated overnight in $80 \%$ acetone at $4{ }^{\circ} \mathrm{C}$ under stirring. The absorbance of their extracts was measured at three wavelengths: $663 \mathrm{~nm}, 646 \mathrm{~nm}$, and $470 \mathrm{~nm}$. The concentrations of chlorophylls and total carotenoids (xanthophylls and carotenes) were determined following the equations given by Lichtenthaler and Wellburn (1983). Measurements were performed in 3 replicates of 6-9 pooled seedlings each.

\subsection{Chlorophyll fluorescence measurements}

Chlorophyll fluorescence was measured $(n=10$, two measurements per plant) using a portable modulated fluorimeter (Mini-PAM, Heinz Walz, Germany) after 3 weeks of treatment. Dark-adapted fluorescence parameters were measured at mid-day (1600 
$\mu \mathrm{mol} \mathrm{m} \mathrm{m}^{-2} \mathrm{~s}^{-1}$ ambient light). Plants were dark-adapted for $30 \mathrm{~min}$ then the minimal $\left(\mathrm{F}_{0}\right)$ $\left(<0.05 \mu \mathrm{mol} \mathrm{m} \mathrm{s}^{-2}\right.$ for $\left.1.8 \mu \mathrm{s}\right)$ and the maximal fluorescence levels $\left(\mathrm{F}_{\mathrm{m}}\right)(10,000 \mu \mathrm{mol}$ $\mathrm{m}^{-2} \mathrm{~s}^{-1}$ for $\left.0.8 \mathrm{~s}\right)$ were measured. The variable fluorescence $\left(\mathrm{F}_{\mathrm{v}}=\mathrm{F}_{\mathrm{m}}-\mathrm{F}_{0}\right)$ and the maximal quantum efficiency of PSII photochemistry $\left(\mathrm{F}_{\mathrm{v}} / \mathrm{F}_{\mathrm{m}}\right)$ were calculated for each measurement couple of $\mathrm{F}_{\mathrm{m}}$ and $\mathrm{F}_{0}$.

\subsection{Phenanthrene localization by fluorescence microscopy}

Microscopy analysis was performed at the Imagif plateform, at the Cellular Biology Pole, (CNRS, Gif sur Yvette, France). Used Arabidopsis tahaliana and Thellungiella salsuginea plants were grown on MS/2 medium for 2 weeks then transferred onto MS/2 medium containing $200 \mu \mathrm{M}$ phenanthrene (data not shown). In order to avoid leaf contamination, a plastic film was applied to separate them from the medium. After one week of phenanthrene treatment, plants of the two species were observed with a Zeiss LSM510 META microscope under UV-light (excitation at $364 \mathrm{~nm}$ and acquisition with 32 channels between 362 and $704 \mathrm{~nm}$ ). Data were acquired using Zen2008 software developed by Zeiss (Germany). Leaves were viewed with a compound microscope under bright field or UV illumination and images were captured with a digital camera. Phenanthrene has a specific fluorescence with blue color. In parallel, to check if phenanthrene was localized in similar tissues or cells in plants grown under low levels

of phenanthrene in the medium, leaves from 3-week-old plants subjected to $25 \mu \mathrm{M}$ phenanthrene were also observed. Fluorescence emission was then detected by an Olympus BX41 spectrofluorometer coupled with a camera. 


\subsection{Singlet oxygen visualization}

Plants treated for 3 weeks with $25 \mu \mathrm{M}$ phenanthrene were immersed and infiltrated in the dark under vacuum in a solution of $100 \mu \mathrm{M}$ Singlet Oxygen Sensor Green ${ }^{\circledR}$ reagent (SOSG) (S36002, Invitrogen) in $50 \mathrm{mM}$ phosphate potassium buffer (pH 7.5). Thereafter, they were placed again on control (MS/2) and treatment (MS/2 $+25 \mu \mathrm{M}$ phenanthrene) media during $30 \mathrm{~min}$ in the light before being photographed under microscope. Following excitation at $480 \mathrm{~nm}$, the fluorescence emission at $530 \mathrm{~nm}$ was then detected by an Olympus BX41 spectrofluorometer coupled with a camera. The presence of red chlorophyll autofluorescence from chloroplasts did not alter the green fluorescence of SOSG (Flors et al., 2006).

\subsection{Superoxide radical visualization}

The nitroblue tetrazolium (NBT) (N6876, Sigma-Aldrich) staining method of Rao and Davis (1999) was used to detect superoxide radical in control and treated plants of the two species that were immersed and infiltrated under vacuum with $3.5 \mathrm{mg} \mathrm{ml}^{-1} \mathrm{NBT}$ staining solution in potassium phosphate buffer $(10 \mathrm{mM})$. After three hours of reaction, plants were bleached in acetic acid-glycerol-ethanol (1/1/3) (v/v/v) solution at $100^{\circ} \mathrm{C}$ during 5 min. The precipitation of NBT with $\mathrm{O}_{2}{ }^{--}$present in plant tissues produces a blue color (Ramel et al., 2009). Plants were then stored in a glycerol-ethanol (1/4) (v/v) solution and photographed.

\subsection{Hydrogen peroxide visualization}

Peroxide radical was detected using 3,3'diaminobenzidine (DAB) (D5637, SigmaAldrich) according to Thordal-Christensen et al. (1997). Plants were immersed and infiltrated under vacuum with $1.25 \mathrm{mg} \mathrm{ml}^{-1} \mathrm{DAB}$ staining solution then were bleached 
in acetic acid-glycerol-ethanol (1/1/3) (v/v/v) solution at $100^{\circ} \mathrm{C}$ during $5 \mathrm{~min}$. Due to DAB polymerization, $\mathrm{H}_{2} \mathrm{O}_{2}$ showed a brown color. Plants were stored in glycerolethanol (1/4) (v/v) solution and were photographed.

\subsection{Determination of MDA concentration}

Leaf malondialdehyde (MDA) concentration was determined using the method of thiobarbituric acid colorimetry (Hodges et al., 1999).

\subsection{Enzymatic assays}

After three weeks of treatment with $25 \mu \mathrm{M}$ phenanthrene, shoots of the two species were harvested and lyophilized. The extraction of soluble proteins was made from 100 $\mathrm{mg}$ of lyophilized material chopped in micro-tubes using $1 \mathrm{ml}$ buffer extraction $(50 \mathrm{mM}$ potassium phosphate buffer (pH 7.5), 1 mM EDTA, PVPP 5\%, 2-mercaptoethanol 4 $\mathrm{mM}$, ascorbate $5 \mathrm{mM}$, protease inhibitor cocktail Sigma P9599 to $5 \mu \mathrm{ml}^{-1}$ added at the time of the extraction). The tubes were placed on a rotary shaker for $1 \mathrm{~h}$ at $4^{\circ} \mathrm{C}$. After centrifugation for $20 \mathrm{~min}$ at $12000 \mathrm{~g}$, the supernatants were retrieved and kept at $-80^{\circ} \mathrm{C}$ until the measurement of antioxidant enzyme activities: guaiacol peroxidase (GPX), glutathione reductase (GR), and superoxide dismutase (SOD). Protein concentration was determined in each enzyme extract according to the colorimetric method of Bradford (Bradford, 1976) using albumin bovine serum as standard.

The activity of SOD was determined by calculating the percentage of inhibition of the reaction followed by the increase of absorbance at $560 \mathrm{~nm}$ according to the method of Giannopolitis and Ries (1977) adapted to 96-well plates. An aliquot of $5 \mu 1$ of enzyme extract was deposited in each well then added with $30 \mu 110 \mathrm{X}$ potassium phosphate buffer, $30 \mu 1$ methionine, and $30 \mu 1$ NBT. The mixture was adjusted to $300 \mu 1$ 
with milliQ water. The final composition of the reaction medium was: $50 \mathrm{mM}$ potassium phosphate ( $\mathrm{pH} 7.8$ ), $0.1 \mathrm{mM}$ Ethylenediaminetetraacetic Acid (EDTA), 75 $\mu \mathrm{M}$ NBT, $13 \mathrm{mM}$ methionine, and $2 \mu \mathrm{M}$ riboflavin. In order to calculate the percentage of inhibition, three wells were prepared with all reagents but without enzyme extracts that were replaced by distilled water. They allowed determining the maximum absorbance of NBT after photochemical reduction. The reaction was initiated by the addition of riboflavin then the mixture was placed under white light, which gave a violet product. The absorbance was measured at $560 \mathrm{~nm}$ before and after 8 minutes of reaction under light. One unit of SOD activity was defined as the amount of enzyme required to inhibit the reduction rate of NBT by $50 \%$.

The activity of GR was measured as maximal rate of Reduced Nicotinamide Adenine Dinucleotide Phosphate (NADPH) disappearance following Vanacker et al. (1998) adapted to 96-well plates. An aliquot of 50 or $100 \mu$ l enzyme extract was added with the necessary reagents to obtain a reaction mixture with the following final composition: 50 mM Hepes buffer ( $\mathrm{pH}$ 8), $0.5 \mathrm{mM}$ EDTA, $0.5 \mathrm{mM}$ GSSG, and $0.25 \mathrm{mM}$ NADPH. The reaction was started by adding $\mathrm{NADPH}, \mathrm{H}^{+}$. The activity of GR was followed as a function of time by absorbance measurement at $340 \mathrm{~nm}$ (a measure every minute for 30 min at $\left.25^{\circ} \mathrm{C}\right)$ following up NADPH disappearance spectrophotometrically at $340 \mathrm{~nm}(\mathrm{E}$ $\left.=6.2 \mathrm{mM}^{-1} \mathrm{~cm}^{-1}\right)$.

The activity of GPX was determined from the maximum speed emergence of tetragaiacol as described by Srivastava and van Huystee (1977) adapted to 96-well plates. Ten microlitres of the enzyme extract were deposited in each well then added with $30 \mu 1$ phosphate buffer, $30 \mu 1$ gaiacol, and $30 \mu 1 \mathrm{H}_{2} \mathrm{O}_{2}$. Thereafter, the mixture was completed to $300 \mu \mathrm{l}$ with milliQ water to obtain a final reaction medium as follows: 100 
$\mathrm{mM}$ potassium phosphate buffer $(\mathrm{pH} 6.5), 15 \mathrm{mM}$ guaiacol, and $0.05 \% \mathrm{H}_{2} \mathrm{O}_{2}(\mathrm{v} / \mathrm{v})$. The reaction was started with the addition of $\mathrm{H}_{2} \mathrm{O}_{2}$ in the reaction mixture. The activity of GPX was followed as a function of time to the VERSA max spectrophotometer (Molecular Devices) by absorbance measurement at $470 \mathrm{~nm}$ (a measurement every 15 seconds for $5 \mathrm{~min}$ at $25^{\circ} \mathrm{C}$ ).

\subsection{Statistical analysis}

A one-way ANOVA analysis was performed using SPSS 16.0 for Windows and means were compared according to Duncan's test at $P \leq 0.05$.

\section{Results}

\subsection{Growth response to phenanthrene-induced stress}

Increased phenanthrene concentration in the culture medium induced a noticeable development inhibition in both species that showed a significant decrease in their sizes, the effect being more pronounced in Arabidopsis thaliana (Fig. 1). Indeed, the glycophyte exhibited a hypersensitive phenotype as all treated plants showed dramatic changes in their sizes and in their fresh weights $(\mathrm{FW})$ that ranged from 22 to $27 \%$ of the control (Fig. 2). By contrast, Thellungiella salsuginea maintained 50\% of its fresh biomass at $25 \mu \mathrm{M}$ phenanthrene and $32-38 \%$ beyond this concentration.

\subsection{Capacity of recovery after phenanthrene treatment}

At the morphological level, Thellungiella salsuginea plants showed a high biomass production after their transfer from the medium containing the highest phenanthrene concentration (100 $\mu \mathrm{M}$ phenanthrene) to the control one (Fig. 3A). This capacity of recovery was estimated on the basis of plant fresh weight $(\mathrm{FW})$ expressed in percent of the control (plant FW in the beginning of the recovery treatment). Results showed that 
Thellungiella salsuginea $\mathrm{FW}$ increased by $150 \%$ during the recovery treatment. By contrast, no recovery was noticed in Arabidopsis thaliana (Fig. 3B).

\subsection{Chlorophyll fluorescence}

Fluorescence measurements revealed no variation with the treatment in the intrinsic quantum yield of PSII (expressed as Fv/Fm ratio) in Thellungiella salsuginea (Fig. 4). In Arabidopsis thaliana, however, this parameter significantly decreased (about $-8.0 \%$ ) beyond $25 \mu \mathrm{M}$ phenanthrene.

\subsection{Pigment contents}

In Arabidopsis thaliana, the concentrations of chlorophyll $a$ (Chla), chlorophyll $b$ $(\mathrm{Chl} b)$, and their sum $(\mathrm{Chl}(a+b))$ showed the same tendency as found for plant growth; no significant difference was observed between plants treated with 25,50 , and $100 \mu \mathrm{M}$ phenanthrene (Table 1). Reductions in these pigments varied from 54.4 to $71.8 \%$. As regards carotenoid concentration, it was substantially affected at $25 \mu \mathrm{M}$ phenanthrene and less affected at 50 and $100 \mu \mathrm{M}$ phenanthrene. The contents of all pigments were less decreased in Thellungiella salsuginea than in Arabidopsis thaliana, except those of carotenoids at 50 and $100 \mu \mathrm{M}$ phenanthrene. Nevertheless, in Thellungiella salsuginea, Chl $b$ concentration was maintained at the same level of the control regardless of the treatment.

\subsection{Visualization of superoxide production}

In the two species, NBT detection showed an increasing blue color with the increasing phenanthrene concentration, indicating a raise of superoxide production with the stress severity (Fig. 5). The effect was more pronounced in Arabidopsis thaliana than in Thellungiella salsuginea. 


\subsection{Visualization of hydrogen peroxide production}

Similarly to NBT detection, DAB staining (brown color) revealed more peroxide production in the glycophyte than in the halophyte; the effect increased as the pollutant concentration increased (Fig. 6). These results suggest that Thellungiella salsuginea involved more efficient ROS scavanging mechanisms as compared to Arabidopsis thaliana.

\subsection{Visualization of singlet oxygen}

The detection of singlet oxygen was performed in plants grown on MS/2 added (Fig. 7B, D, F and H) or not (Fig. 7A, C, E, and G) with $25 \mu \mathrm{M}$ phenanthrene. The fluorescence of SOSG corresponds to the green coloration, while the red color stands for chlorophyll autofluorescence. Arabidopsis thaliana fluorescence increased in trichomes, in particular in their basal cells (Fig. 7D) as compared to the control (Fig. 7C). However, in Thellungiella salsuginea, singlet oxygen was mainly localized in stomata cells and the fluorescence of this species (Fig. 7F) showed lower intensity in comparison with that of Arabidopsis thaliana (Fig. 7B).

\subsection{SOD, GR, and GPX activities}

Phenanthrene treatment increased SOD activity by 36.6 and $33.7 \%$ respectively in the glycophyte and the halophyte (Fig. 8). As regards GR activity, a marked phenanthreneinduced amplification was noticed in Arabidopsis thaliana (95.3\%), whereas no variation was recorded in Thellungiella salsuginea (Fig. 8). Similar results were found for GPX activity that showed no significant variation in Thellungiella salsuginea and an augmentation of $73.5 \%$ in Arabidopsis thaliana (Fig. 8). 


\subsection{MDA concentration}

MDA concentrations were maintained constant (3.2-4.0 $\left.\mathrm{nmol} \mathrm{g} \mathrm{g}^{-1} \mathrm{FW}\right)$ in both species regardless of the treatment (Fig. 9).

\subsection{Localization of phenanthrene accumulation}

At $25 \mu \mathrm{M}$ phenanthrene, the observations of the two species using fluorescence microscopy showed no PAH accumulation in Arabidopsis thaliana tissues but an obvious accumulation in stomata of Thellungiella salsuginea (Fig. 10C, D, E, F, and G). However, at $200 \mu \mathrm{M}$, blue trypan specific fluorescence allowed the detection of phenanthrene in trichomes of Arabidopsis thaliana (data not shown).

\section{Discussion}

This comparative study was performed to check whether halophytes are better candidates for PAH phytoremediation than glycophytes. To make the comparison more reasonable, the glycophytic model plant $A$. thaliana and its close relative halophytic $T$. salsuginea (Orsini et al., 2010) were used. Short life cycle, self-fertility, and being genetically transformable are criteria that make $T$. salsuginea exemplary (Inan et al., 2004). Relatively small genome size, about twice that of $A$. thaliana, and the availability of ecotypes with a range of stress responses constitute additional criterion that make $T$. salsuginea an excellent model for a better understanding of abiotic stress tolerance in plants (Wu et al., 2012). In this study, the two model species were grown on MS medium under controlled conditions to avoid any involvement of biotic and/or abiotic factors that can influence plant responses to phenanthrene stress. Our investigation could form a first step in the understanding of the higher PAH tolerance in halophytes 
as compared to glycophytes and make halophytism among the major criterion for the selection of useful plants for PAH phytoremediation.

Arabidopsis thaliana responses to phenanthrene have already been investigated. Phenanthrene-treated plants exhibited many sensitive symptoms, such as growth and leaf number reduction and root and trichome deformation (Liu et al., 2009; Weisman et al., 2010). Concentrations higher than $0.05 \mathrm{mM}$ were very toxic and lethal for plants after $30 \mathrm{~d}$ of treatment (Alkio et al., 2005). However, no data on halophytic plant responses to this pollutant and to PAHs in general are available. Hence, this is the first report describing the behavior of a halophytic model plant subjected to phenanthrene. Comparing the two species, we found that Thellungiella salsuginea showed higher tolerance to phenanthrene-induced stress than Arabidopsis thaliana. This was observed at 3 different levels: 1) growth and pigment content, 2) oxidant stress severity and antioxidant response, and 3) phenanthrene localization.

Biomass production and pigment concentrations were significantly more affected in the glycophyte than in the halophyte. In literature, different degrees of sensitivity to phenanthrene were described depending on plant species. For instance, in a comparative study performed on 4 crops (corn, groundnut, cow pea, and mungbean) grown on acidic soil, Chouychai et al. (2007) found the lowest phenanthrene phytotoxicity in corn. They concluded that it is the most suitable crop species to be grown on PAH-contaminated acidic soil. Song et al. (2005) also compared the phytotoxicities of phenanthrene, pyrene, and their mixture in five crops (Chinese cabbage, green onion, tomato, turnip, and wheat). They found phenanthrene more phytotoxic than pyrene and wheat the most sensitive species. Phytotoxicity is in fact due to an excessive accumulation of phenanthrene in plant tissues and plants respond to pollutants only after being exposed 
to the "threshold concentration" that varies with both pollutant and species (Muratova et al., 2009). In this context, it was established that a fast accumulation phase of phenanthrene occurs during the first hours (the first two hours in the case of wheat) of treatment, followed by a slower one. Its uptake by plant roots is certainly realized through a passive mechanism; however an involvement of active mechanisms is also likely (Zhan et al., 2010). This suggests that Thellungiella salsuginea and Arabidopsis thaliana accumulated high quantities of the pollutant during the first hours of treatment, which can explain the noticeable reduction in their fresh weights. But, the differences in their responses to the stress in terms of biomass production can be attributed to a probable lower accumulation and/or a better management of the accumulated quantity of phenanthrene by the halophyte in comparison with the glycophyte, including metabolization by cell-enzymes, vacuole-sequestration, and volatilization by stomata (Muratova et al., 2009). The lipophilic PAH nature can indirectly disturb biomembrane structure as a consequence of the formation of free radicals induced by these molecules and their derivatives (Tukaj and Aksmann, 2007). To limit damages caused by ROS, plant cells produce antioxidant enzymes (e.g. superoxide dismutase (SOD), catalase (CAT), gaiacol peroxidase (GPX), glutathione reductase (GR), and glutathione-stransferase (GST)), as well as non-enzymatic antioxidants (e.g. glutathione and ascorbate). They represent molecular bioindicators for contaminant-mediated oxidative stress (Alkio et al., 2005; Shao et al., 2002). In this study, Arabidopsis thaliana showed higher superoxide, hydrogen peroxide, and singlet oxygen accumulation under phenanthrene stress conditions as compared to Thellungiella salsuginea. These results were concomitant with those of chlorophyll fluorescence that indicated a maintained functional integrity of PSII in the halophyte and its slight disturbance in the glycophyte. 
To maintain MDA concentration constant under phenanthrene stress conditions, Arabidopsis thaliana experienced a marked increase in SOD, GR, and GPX activities, whereas Thellungiella salsuginea showed only a slight increase in SOD activity. These data confirm that phenanthrene phytotoxicity was higher in the glycophyte than in the halophyte.

As regards phenanthrene localization in Arabidopsis thaliana, it was mainly accumulated in trichomes. However, its accumulation is function of time and concentration in the medium. This can explain why this pollutant was not detected in trichomes of plants at $25 \mu \mathrm{M}$ after 3 weeks of treatment. It can be due to its degradation by plant cells (Alkio et al., 2005). In Thellungiella salsuginea, an obvious phenanthrene accumulation was observed in stomata where it may be probably diffused in the atmosphere. It can also explain the higher recovery potential of the halophyte as compared to the glycophyte that did not recover, which suggests that the two species adopt two different strategies to cope with phenanthrene. Indeed, phenanthrene bioaccumulation depends on its concentration and on treatment period. Fismes et al. (2002) proposed that the transport of low molecular weight PAHs like phenanthrene from root system to leaves could be passive and driven by transpiration flux. The halophytic model plant Thellungiella salsuginea experienced higher stomata density than Arabidopsis thaliana and the transpiration rate of halophytic species was shown to be generally lower (about 60\%) than that of the glycophytic plant Arabidopsis thaliana (Orsini et al., 2010). This morphological difference offered to the halophytic model plant the possibility to better manage phenanthrene transport and could explain its localization in stomata. Gutierrez-Alcala and colleagues (2000) demonstrated that Arabidopsis thaliana trichomes contain at least 300-fold increased glutathione 
concentrations compared to other epidermal cells and suggested that trichome function consists of a site of xenobiotic conjugation.

In conclusion, all these data taken together, add new insights into 1) the mechanisms evolved by halophytic plants to tolerate abiotic stresses, in particular PAH stress, and 2) the usefulness of this ecological group as potential bioresource for phytoremediation programs. Hence, halophytism can be used as a major criterion for the selection of candidate plants for PAH phytoremediation. Moreover, the need of halophytes becomes inevitable if the contaminated site is salt-affected.

\section{References}

Alkio, M., Tabuchi, T.M., Wang, X., Colon-Carmona A., 2005. Stress responses to polycyclic aromatic hydrocarbons in Arabidopsis include growth inhibition and hypersensitive response-like symptoms. J. Exp. Bot. 56(421), 2983-2994. doi: 10.1093/jxb/eri295

Amtmann, A., 2009. Learning from evolution: Thellungiella generates new knowledge on essential and critical components of abiotic stress tolerance in plants. Mol. Plant 2, 3-12. doi: 10.1093/mp/ssn094

Batish, D.R., Singh, H.P., Setia, N., Kaur, S., Kohli, R.K., 2006. Chemical composition and phytotoxicity of volatile essential oils from intact and fallen leaves of Eucalyptus citriodora. Z. Naturforsch C. 61, 465-471.

Ben Hamed, K., Ellouzi, H., Zribi Talbi, O., Hessini, K., Slama, I., Ghnaya, T., Bosch, S., Savouré, A., Abdelly, C., 2013. Physiological response of halophytes to multiple stresses. Funct. Plant Biol. 40, 883-896. 
Bhargava, A., Carmona, F.F., Bhargava, M., Srivastava, S., 2012. Approaches for enhanced phytoextraction of heavy metals. J. Environ. Manage. 105, 103-120. doi: 10.1016/j.jenvman.2012.04.002

Bradford, M.M., 1976. A rapid and sensitive method for the quantitation of microgram quantities of protein utilizing the principle of protein-dye binding. Anal. Biochem. 72, 248-54. doi: 10.1016/0003-2697(76)90527-3

Burrit, D.J., 2008. The polycyclic aromatic hydrocarbon phenanthrene causes oxidative stress and alters polyamine metabolism in the aquatic liverwort Riccia fluitans L. Plant Cell Environ. 31, 1416-1431. doi: 10.1111/j.1365-3040.2008.01846.x.

Cheema, S.A., Khan, M.I., Shen, C.F., Tang, X.J., Farooq, M., Chen, L., Zhang, C.K., Chen, Y.X., 2010. Degradation of phenanthrene and pyrene in spiked soils by single and combined plants cultivation. J. Hazard. Mater. 177, 384-389. doi: 10.1016/j.jhazmat.2009.12.044

Chouychai, W., Thongkukiatkul, A., Upatham, S., Lee, H., Pokethitiyook, P., Kruatrachue, M., 2007. Phytotoxicity assay of crop plants to phenanthrene and pyrene contaminants in acidic soil. Environ. Toxicol. 22(6), 597-604. doi: 10.1002/tox.20285

Das, D.N., Panda, P.K., Mukhopadhyay, S., Sinha, N., Mallick, B., Behera, B., Maiti, T.K., Bhutia, S.K., 2014. Prediction and validation of apoptosis through cytochrome P450 activation by benzo[a]pyrene. Chem. Biol. Interact. 208, 8-17. doi: 10.1016/j.cbi.2013.11.005

El-Bakatoushi, R., 2011. Identification and characterization of up-regulated genes in the halophyte Limoniastrum monopetalum (L) Boiss grown under crude oil pollution. J. Genet. Engin. Biotechnol. 9(2), 137-148. doi:10.1016/j.jgeb.2011.10.001 
Fismes, J., Perrin-Ganier, C., Empereur-Bissonnet, P., Morel, J.L., 2002. Soil-to-Root Transfer and Translocation of Polycyclic Aromatic Hydrocarbons by Vegetables Grown on Industrial Contaminated Soils. J. Environ. Qual. 31, 1649-1656.

Flors, C., Fryer, M.J., Waring, J., Reeder, B., Bechtold, U., Mullineaux, P.M., Nonell, S., Wilson, M.T., Baker, N.R., 2006. Imaging the production of singlet oxygen in vivo using a new fluorescent sensor, Singlet Oxygen Sensor Green. J. Exp. Bot. 57(8), 17251734. doi:10.1093/jxb/erj181

Gan, H.M., Buckley, L., Szegedi, E., Hudson, A.O., Savka M.A., 2009. Identification of an rsh gene from a Novosphingobium sp. necessary for quorum sensing signal accumulation. J. Bacteriol. doi:10.1128/JB.01692-08

Giannopolitis, C.N., Ries, S.K., 1977. Superoxide Dismutases, I. Occurrence in higher plants. Plant Physiol. 59, 309-314. doi: 10.1104/pp.59.2.309

Gutierrez-Alcala, G., Gotor, C., Meyer, A.J., Fricker, M., Vega, J.M., Romero, L.C., 2000. Glutathione biosynthesis in Arabidopsis trichome cells. Proc. Natl. Acad. Sci. USA 97, 11108-11113. doi: 10.1073/pnas.190334497

Harvey, R.G., 1991. Polycyclic aromatic hydrocarbons: chemistry and carcinogenicity. Cambridge University Press, Cambridge.

Herbinger, K., Tausz, M., Wonisch, A., Soja, G., Sorger, A., Grill, D., 2002. Complex interactive effects of drought and ozone stress on the antioxidant defense systems of two wheat cultivars. Plant Physiol. Biochem. 40, 691-696. doi: 10.1016/S09819428(02)01410-9

Hodges, D.M., DeLong, J.M., Forney, C.F., Prange, R.K., 1999. Improving the thiobarbituric acid-reactive-substances assay for estimating lipid peroxidation in plant 
tissues containing anthocyanin and other interfering compounds. Planta 207, 604-611. doi: $10.1007 / \mathrm{s} 004250050524$

Howes Keiffer, C., Ungar, I.A., 2002. Germination and establishment of halophytes on brine-affected soils. J. Appl. Ecol. 39, 402- 415. doi: 10.1046/j.13652664.2002.00720.x

Inan, G., Zhang, Q., Li, P., Wang, Z., Cao, Z., Zhang, H., Zhang, C., Quist, T.M., Goodwin, S.M., Zhu, J., Shi, H., Damsz, B., Charbaji, T., Gong, Q., Ma, S., Fredricksen, M., Galbraith, D.W., Jenks, M.A., Rhodes, D., Hasegawa, P.M., Bohnert, H.J., Joly, R.J., Bressan, R.A., Zhu, J.K., 2004. Salt cress. A halophyte and cryophyte arabidopsis relative model system and its applicability to molecular genetic analyses of growth and development of extremophiles. Plant Physiol. 135, 1718-1737.

Kathi, S., Khan, A.B., 2011. Phytoremediation approaches to PAH contaminated soil. Ind. J. Sci. Technol. 4(1), 56-63.

Li, J., Fan, R., Lu, S., Zhang, D., Zhou, Y., Lv, Y., 2014. Exposure to polycyclic aromatic hydrocarbons could cause their oxidative DNA damage: a case study for college students in Guangzhou, China. Environ.Sci Pollut. Res. doi 10.10007/s11356$014-2769-\mathrm{z}$

Lichtenthaler, H.K., Wellburn, A.R., 1983. Determinations of total carotenoids and chlorophylls $a$ and $b$ of leaf extracts in different solvents. Biochem. Soc. Trans. 11, $591-592$.

Liu, H., Weisman, D., Ye, Y., Cui, B., Huang, Y., Colon-Carmona, A., Wang, Z., 2009. An oxidative stress response to polycyclic aromatic hydrocarbon exposure is rapid and 
complex in Arabidopsis thaliana. Plant Sci. 176, 375-82. doi: 10.1016/j.plantsci.2008.12.002

Livingstone, D.R., 2001. Contaminant-stimulated reactive oxygen species production and oxidative damage in aquatic organisms. Mar. Pollut. Bull. 42, 656-666. doi: $10.1016 / \mathrm{S} 0025-326 \mathrm{X}(01) 00060-1$

Manousaki, E., Kalogerakis, N., 2010. Halophytes present new opportunities in phytoremediation of heavy metals and saline soils. Ind. Eng. Chem. Res. 50(2), 656660. doi: 10.1021/ie100270x

Marwood, C.A., Solomon, K.R., Greenberg, B.M., 2001. Chlorophyll fluorescence as a bioindicator of effects on growth in aquatic macrophytes from mixtures of polycyclic aromatic hydrocarbons. Environ. Toxicol. Chem. 20 (4), 890-8.

Muratova, A.Y., Kapitonova, V., Chernyshova, M., Turkovskaya, O.V., 2009. Enzymatic activity of alfalfa in a phenanthrene-contaminated environment. World Acad. Sci. Eng. Technol. 58, 569-574.

Orsini, F., D’Urzo, M.P., Inan, G., Serra, S., Oh, D.H., Mickelbart, M.V., Consiglio, F., Li, X., Jeong, J.C., Yun, D.J., Bohnert, H.J., Bressan, R.A., Maggio, A., 2010. A comparative study of salt tolerance parameters in 11 wild relatives of Arabidopsis thaliana. J. Exp. Bot. 61, 3787-3798.

Posada-Baquero, R., Ortega-Calvo, J.J., 2011. Recalcitrance of polycyclic aromatic hydrocarbons in soil contributes to background pollution. Environ. Pollut. 159, 36923699. doi:10.1111/j.1574-6968.2007.00750.x 
Paskova, V., Hilscherova, K., Feldmannova, M., Blaha, L., 2006. Toxic effects and oxidative stress in higher plants exposed to polycyclic aromatic hydrocarbons and their $N$-heterocyclic derivatives. Environ. Toxicol. Chem. 25, 3238-3245. doi: 10.1897/06-162R.1

Ramel, F., Sulmon, C., Bogard, M., Couée, I., Gouesbet, G., 2009. Differential patterns of reactive oxygen species and antioxidative mechanisms during atrazine injury and sucrose-induced tolerance in Arabidopsis thaliana plantlets. BMC Plant Biol. 9, 28 doi: $10.1186 / 1471-2229-9-28$

Rao, M.V., Davis, K.R., 1999. Ozone-induced cell death occurs via two distinct mechanisms in Arabidopsis: the role of salicylic acid. Plant J. 1999. 17(6), 603-614.

Redondo-Gómez, S., Andrades-Moreno, L., Parra, R., Valera-Burgos, J., Real, M., Mateos-Naranjo, E., Cox, L., Corneio, J., 2011. Spartina densiflora demonstrates high tolerance to phenanthrene in soil and reduces it concentration. Mar. Pollut. Bull. 62(8), $1800-1808$.

Shao, Z.H., Vanden Hoek, T.L., Qin, Y., Becker, L.B, Schumacker, P.T., Li, C.Q., Dey, L., Barth, E., Halpern, H., Rosen, G.M., Yuan, C.S., 2002. Baicalein attenuates oxidant stress in cardiomyocytes. Am. J. Physiol. Heart Circ. Physiol. 282, H999-H1006

Shim, J.S., Jung, C., Lee, S., Min, K., Lee, Y.W., Choi, Y., 2012. AtMYB44 regulates WRKY70 expression and modulates antagonistic interaction between salicylic acid and jasmonic acid signaling. Plant J. 73, 483-495. doi: 10.1111/tpj.12051

Selote, D.S., Bharti, S., Chopra, R.K., 2004. Drought acclimation reduces $\mathrm{O}_{2}$ accumulation and lipid peroxidation in wheat seedlings. Biochem. Biophys. Res. Commun.314, 724-729. doi: 10.1016/j.bbrc.2003.12.157 
Seo, J.S., Keum, Y.S., Li, Q.X., 2009. Bacterial degradation of aromatic compounds. Int. J. Environ. Res. Public Health. 6, 278-309; doi:10.3390/ijerph6010278

Song, Y.F., Gong, P., Zhou, Q.X., Sun, T.H., 2005. Phytotoxicity assessment of phenanthrene, pyrene and their mixtures by a soil-based seedling emergence test, $\mathrm{J}$. Environ. Sci. 17(4), 580-583. doi: 10.1111/j.1399-3054.1980.tb08651.x

Srivastava, O.P., van Huystee, R.B., 1977. IAA oxidase and polyphenol oxidase activities of peanut peroxidase isoenzymes. Phytochem. 16, 1527-1530.

Thordal-Christensen, H., Zhang, Z., Wei, Y., Collinge, D.B., 1997. Subcellular localization of $\mathrm{H}_{2} \mathrm{O}_{2}$ in plants, $\mathrm{H}_{2} \mathrm{O}_{2}$ accumulation in papillae and hypersensitive response during barley-powdery mildew interaction. Plant J. 11, 1187-1194.

Tukaj, Z., Aksmann, A., 2007. Toxic effects of anthraquinone and phenanthrenequinone upon Scenedesmus strains (green algae) at low and elevated concentration of $\mathrm{CO}_{2}$. Chemosphere 66(3), 480-7. doi: 10.1016/j.chemosphere.2006.05.072

Vanacker, H., Carver, T.L.W., Foyer, C.H., 1998. Pathogen-induced changes in the antioxidant status of the apoplast in barley leaves. Plant Physiol. 117, 1103-1114.

Vangronsveld, J., Herzig, R., Weyens, N., Boulet, J., Adriaensen, K., Ruttens, A., Thewys, T., Vassilev, A., Meers, E., Nehnevajova, E., van der Lelie, D., Mench, M., 2009. Phytoremediation of contaminated soils and groundwater: lessons from the field. Environ. Sci. Pollut. Res. Int. 16(7), 765-94. doi: 10.1007/s11356-009-0213-6

Weisman, D., Alkio, M., Colón-Carmona, A., 2010. Transcriptional responses to polycyclic aromatic hydrocarbon-induced stress in Arabidopsis thaliana reveal the involvement of hormone and defense signaling pathways. BMC Plant Biol., doi: $10.1186 / 1471-2229-10-59$. 
Wittig, R., Ballach, H.J., Kuhn, A., 2003. Exposure of the roots of Populus nigraL. cv. Loenen to PAHs and its effect on growth and water balance. Environ. Sci. Pollut. Res. Int. 10, 235-244. doi: dx.doi.org/10.1065/espr2003.04.150.1

Wu, H.J., Zhang, Z., Wang, J.Y., Oh, D.H., Dassanayake, M., Liu, B., Huang, Q., Sun, H.X., Xia, R., Wu, Y., Wang, Y.N., Yang, Z., Liu, Y., Zhang, W., Zhang, H., Chu, J., Yan, C., Fang, S., Zhang, J., Wang, Y., Zhang, F., Wang, G., Lee, S.Y., Cheeseman, J.M., Yang, B., Li, B., Min, J., Yang, L., Wang, J., Chu, C., Chen, S.Y., Bohnert, H.J., Zhu, J.K., Wang, X.J., Xie, Q., 2012. Insights into salt tolerance from the genome of Thellungiella salsuginea. Proc. Natl. Acad. Sci. 109(30), 12219-12224. doi: 10.1073/pnas. 1209954109

Youssef, T., 2002. Evidence for reduced post-spill recovery by the halophyte Sporobolus iocladus (Nees ex Trin.) Nees in oil-contaminated sediments. Mar. Pollut. Bull. 44, 334-339. doi: dx.doi.org/10.1016/s0025-326x(01)00265-x

Zhan, X.H., Ma, H.L., Zhou, L.X., Liang, J.R., Jiang, T.H., Xu, G.H., 2010. Accumulation of phenanthrene by roots of intact wheat (Triticum acstivnm L.) seedlings: passive or active uptake? BMC Plant Biol. 10:52. doi:10.1186/1471-2229-1052 


\section{Figure legends}

Figure 1. The effects of increasing phenanthrene concentrations $(0,25,50$, and 100 $\mu \mathrm{M})$ on Arabidopsis thaliana (A) and Thellungiella salsuginea (B). Scale bars $=1 \mathrm{~cm}$.

Figure 2. The effects of increasing phenanthrene concentrations $(0,25,50$, and 100 $\mu \mathrm{M})$ on fresh weights. Bars are means of 20 replicates \pm SE. Bars labeled by different letters are significantly different according to Duncan's test at $P \leq 0.05$.

Figure 3. Recovery potential in plants grown for 2 weeks at $100 \mu \mathrm{M}$ phenanthrene then for 4 weeks on control medium. A. Phenotype recovery after phenanthrene-induced stress. B. Fresh weights of recovered plants in percent of their initial ones before their transfer onto phenanthrene-free medium (control). Bars are means of 3 replicates \pm SE. Bars labeled by different letters are significantly different according to Duncan's test at $P \leq 0.05$.

Figure 4. The effects of increasing phenanthrene concentrations $(0,25,50$, and 100 $\mu \mathrm{M}$ ) on the intrinsic quantum yield of PSII (expressed as Fv/Fm). Bars are means of 10 replicates \pm SE. Bars labeled by different letters are significantly different according to Duncan's test at $P \leq 0.05$.

Figure 5. Visualization of leaf superoxide production under increasing phenanthreneinduced stress $(0,25,50$, and $100 \mu \mathrm{M})$ by NBT detection.

Figure 6. Visualization of leaf production of hydrogen peroxide under increasing phenanthrene-induced stress $(0,25,50$, and $100 \mu \mathrm{M})$ by DAB staining.

Figure 7. Visualization of leaf singlet oxygen with SOSG fluorescent probe detection at $0 \mu \mathrm{M}(\mathrm{A}, \mathrm{C}, \mathrm{E}$, and $\mathrm{G})$ and $25 \mu \mathrm{M}$ phenanthrene $(\mathrm{B}, \mathrm{D}, \mathrm{F}$, and H). Scale bars $=100 \mu \mathrm{m}$. 
Figure 8. Leaf enzymatic activities of SOD, GR, and GPX under moderate phenanthrene treatment $(25 \mu \mathrm{M})$.

Figure 9. The effects of a moderate phenanthrene concentration $(25 \mu \mathrm{M})$ on leaf MDA accumulation. Bars are means of 4 replicates \pm SE. Bars labeled by different letters are significantly different according to Duncan's test at $P \leq 0.05$.

Figure 10. Phenanthrene fluorescence in Arabidopsis thaliana (A and B) and Thellungiella salsuginea (C, D, E, F, and G) leaves after 3 weeks of growth at $25 \mu \mathrm{M}$ phenanthrene. A. Arabidopsis thaliana leaf showing no phenanthrene fluorescence. B. A detail of an Arabidopsis thaliana trichome showing no phenanthrene fluorescence. C. Different stages of fluorescence accumulation on a Thellungiella salsuginea leaf. D. Evolution of fluorescence accumulation in stomata (shown by circles) of Thellungiella salsuginea. E, F, and G: Details of Thellungiella salsuginea stomata showing increasing phenanthrene accumulation. Scale bars correspond to $100 \mu \mathrm{m}$ (A and C), 10 $\mu \mathrm{m}(\mathrm{B}$ and $\mathrm{D})$, and $20 \mu \mathrm{m}(\mathrm{E}, \mathrm{F}$, and $\mathrm{G})$. 
Figure 1.
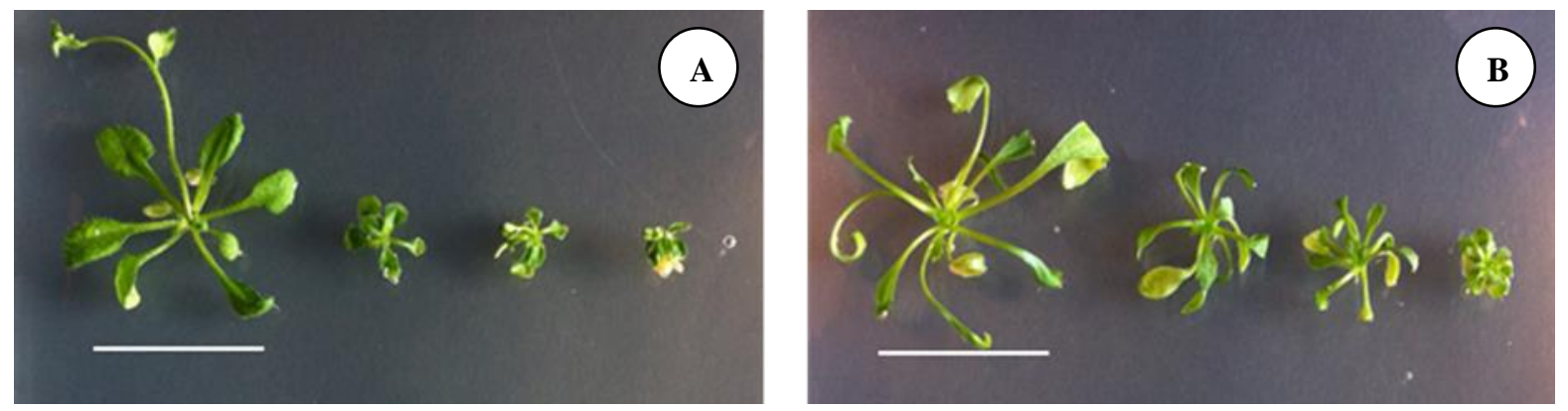
Figure 2.

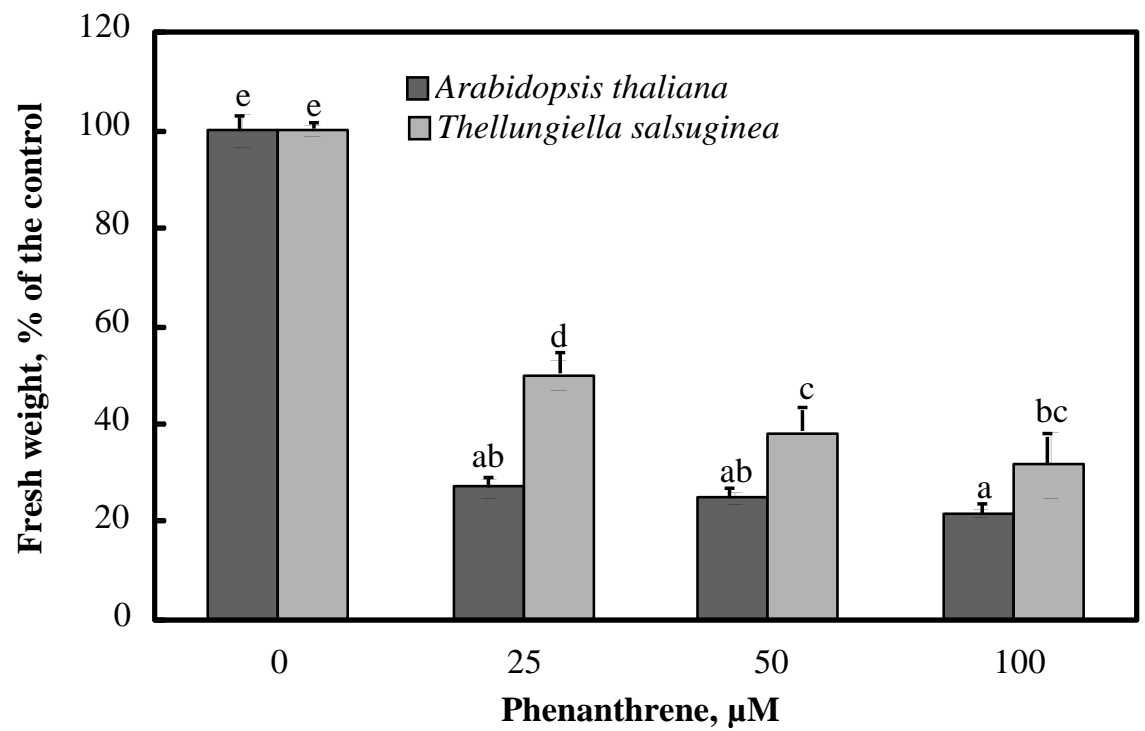


Figure 3.
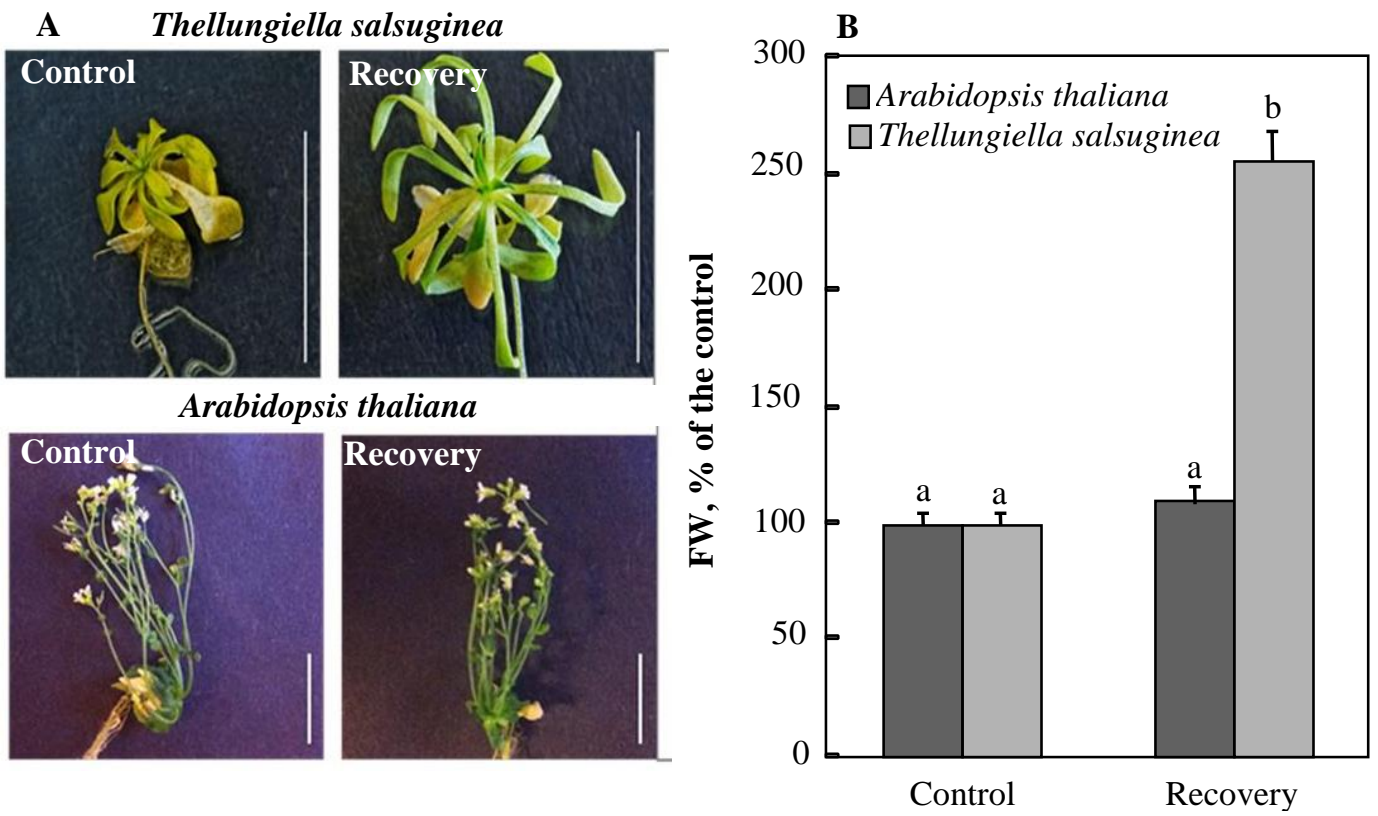
Figure 4.

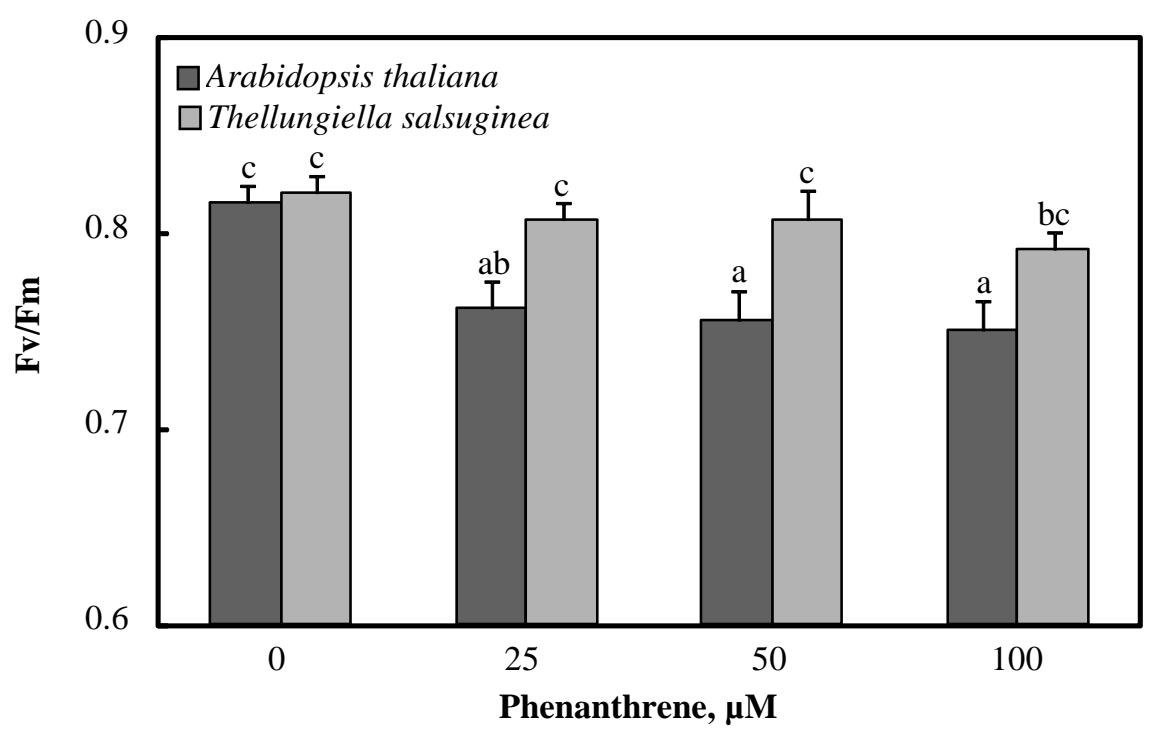


Figure 5.

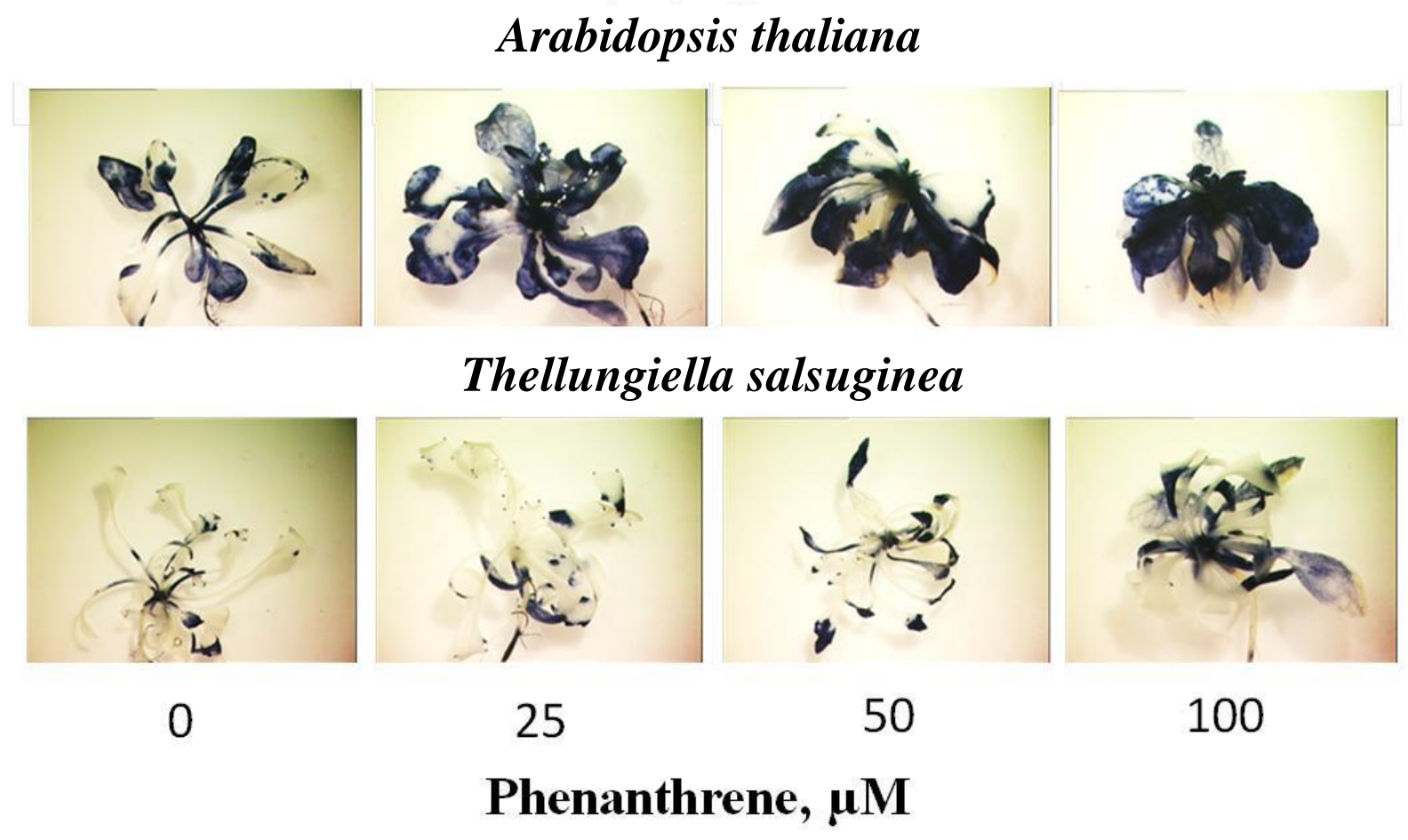


Figure 6.

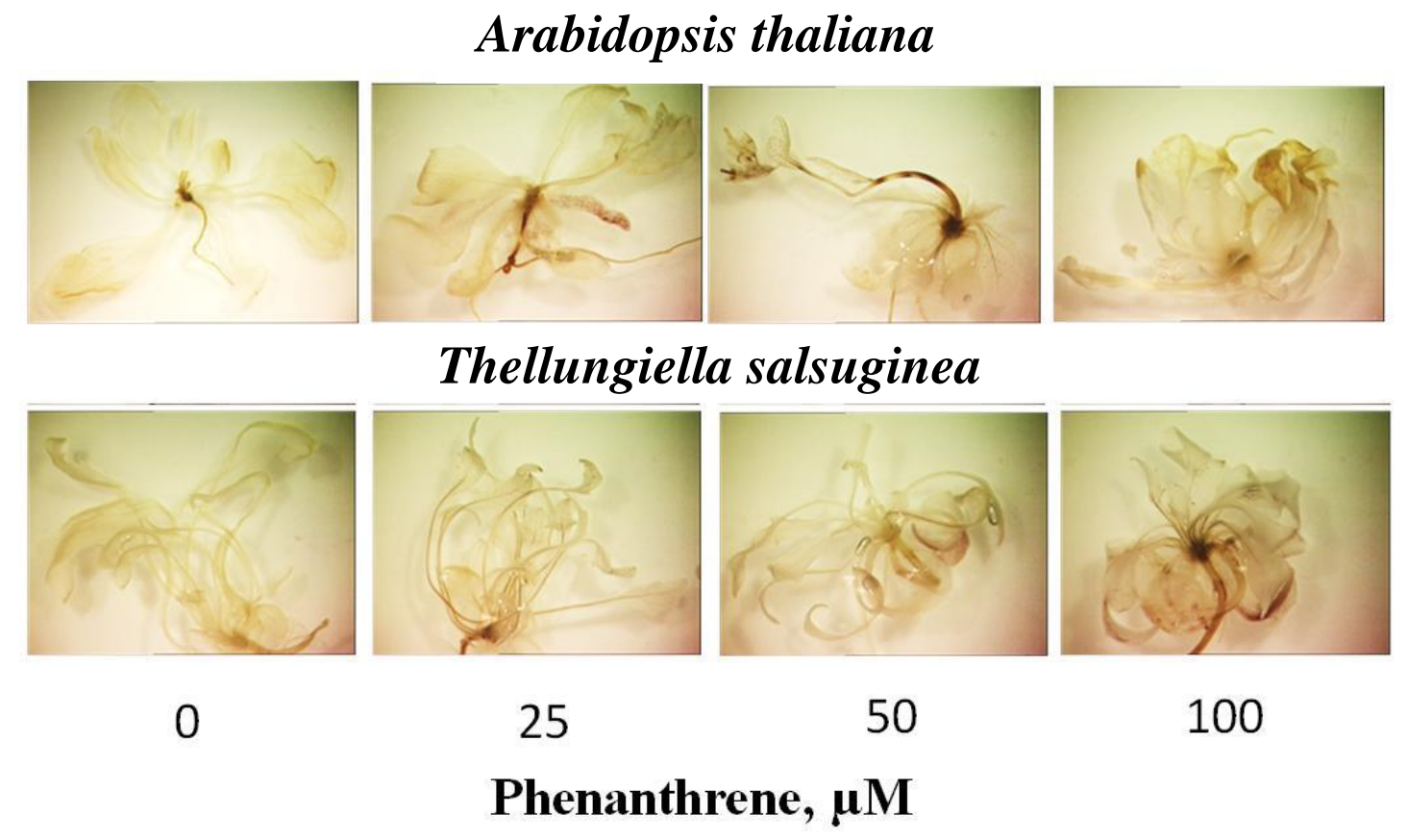


Figure 7.

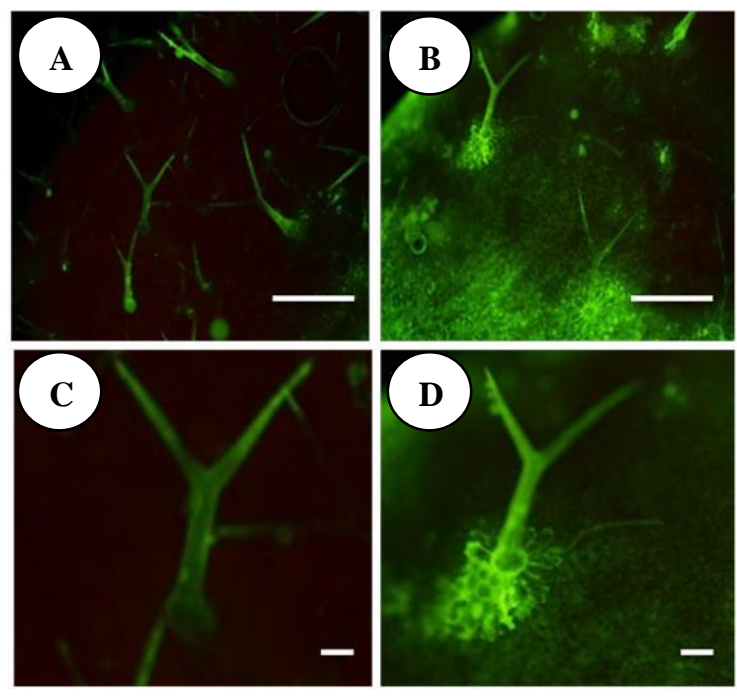

Arabidopsis thaliana

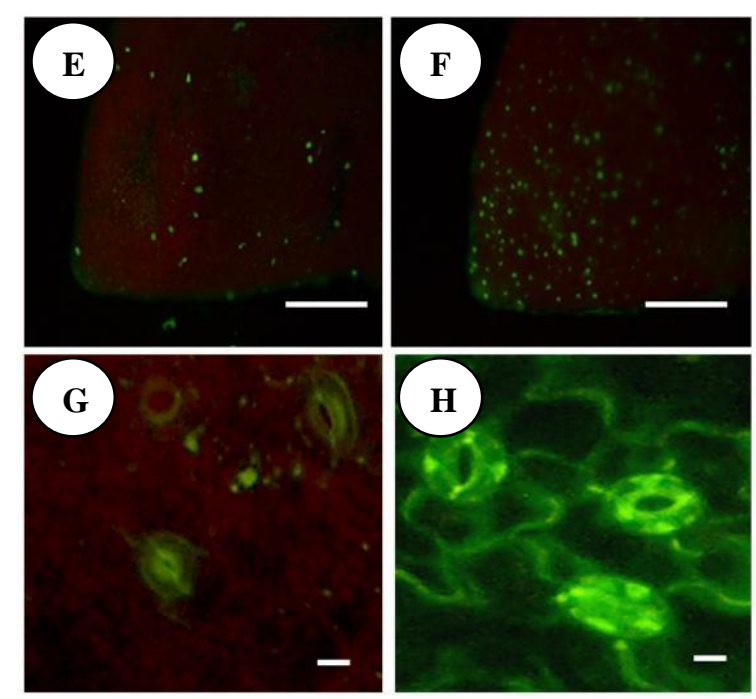

Thellungiella salsuginea 
Figure 8.
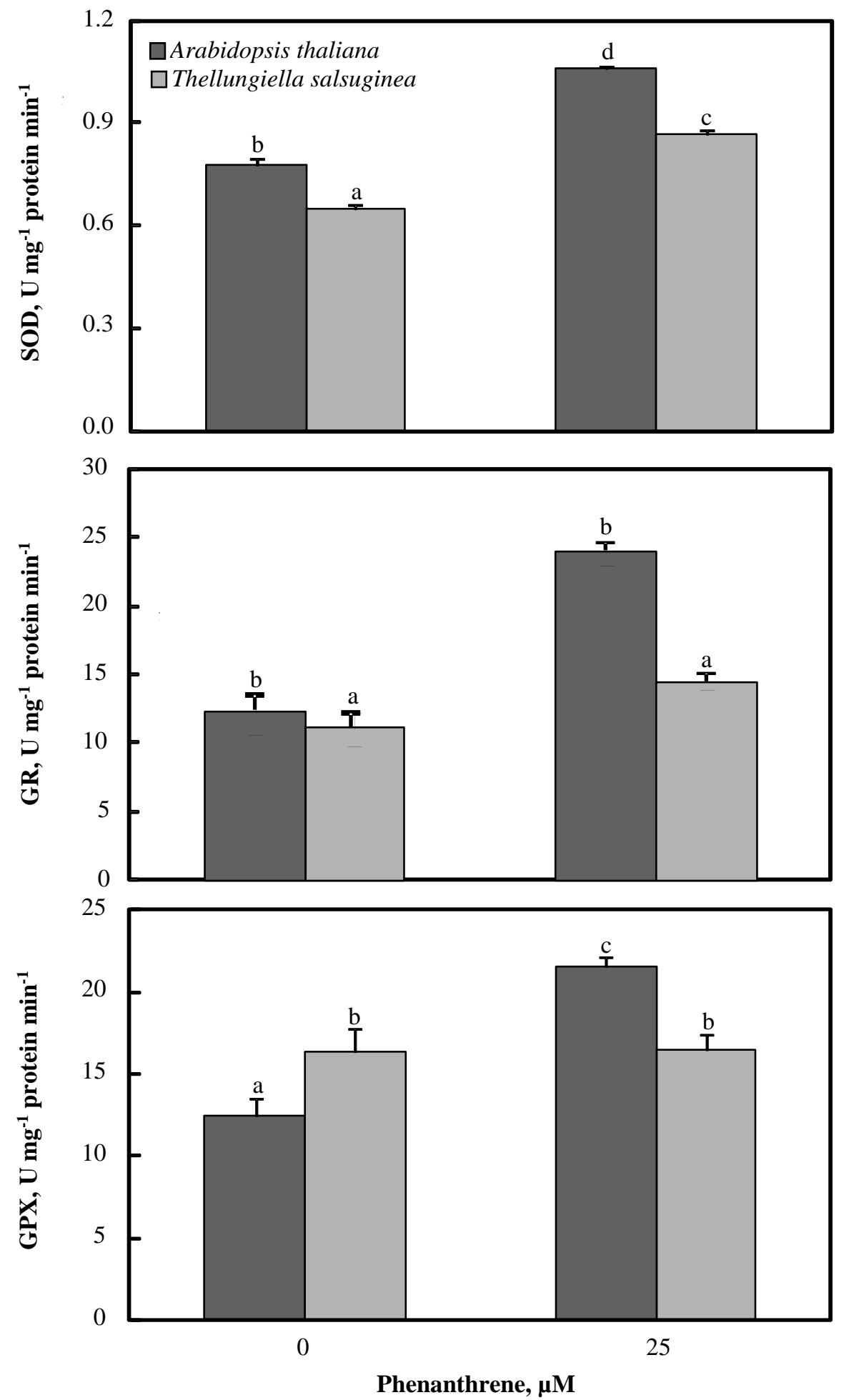
Figure 9.

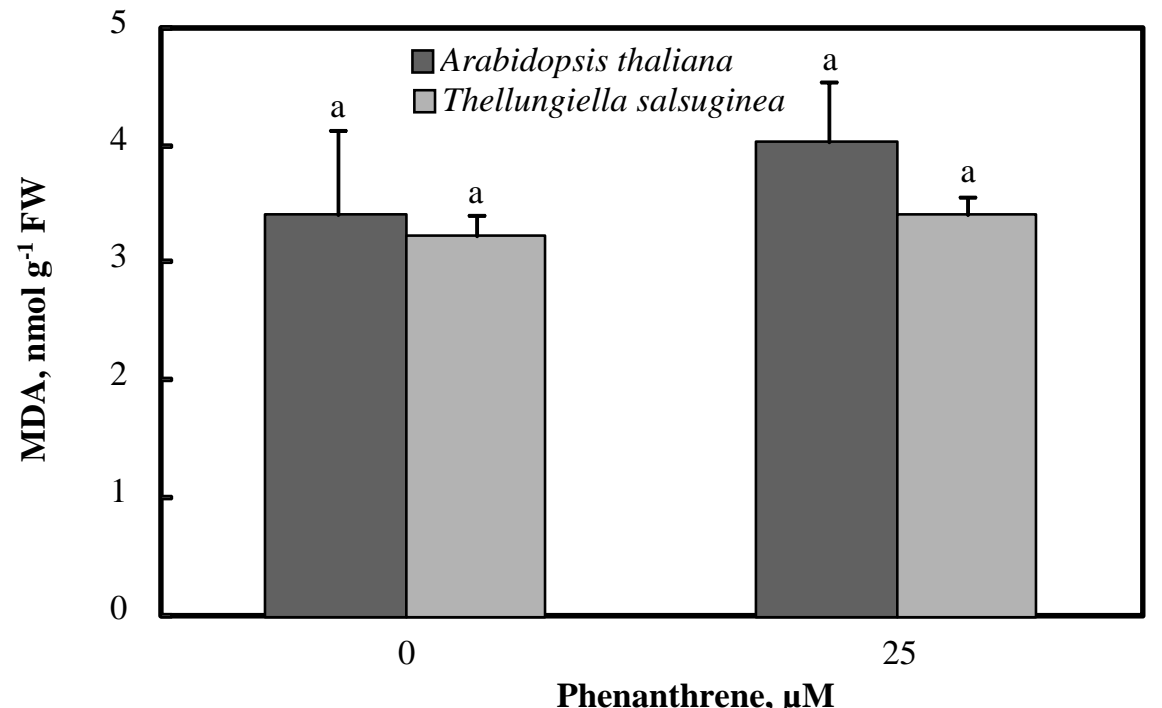

Phenanthrene, $\mu \mathrm{M}$ 
Figure 10.

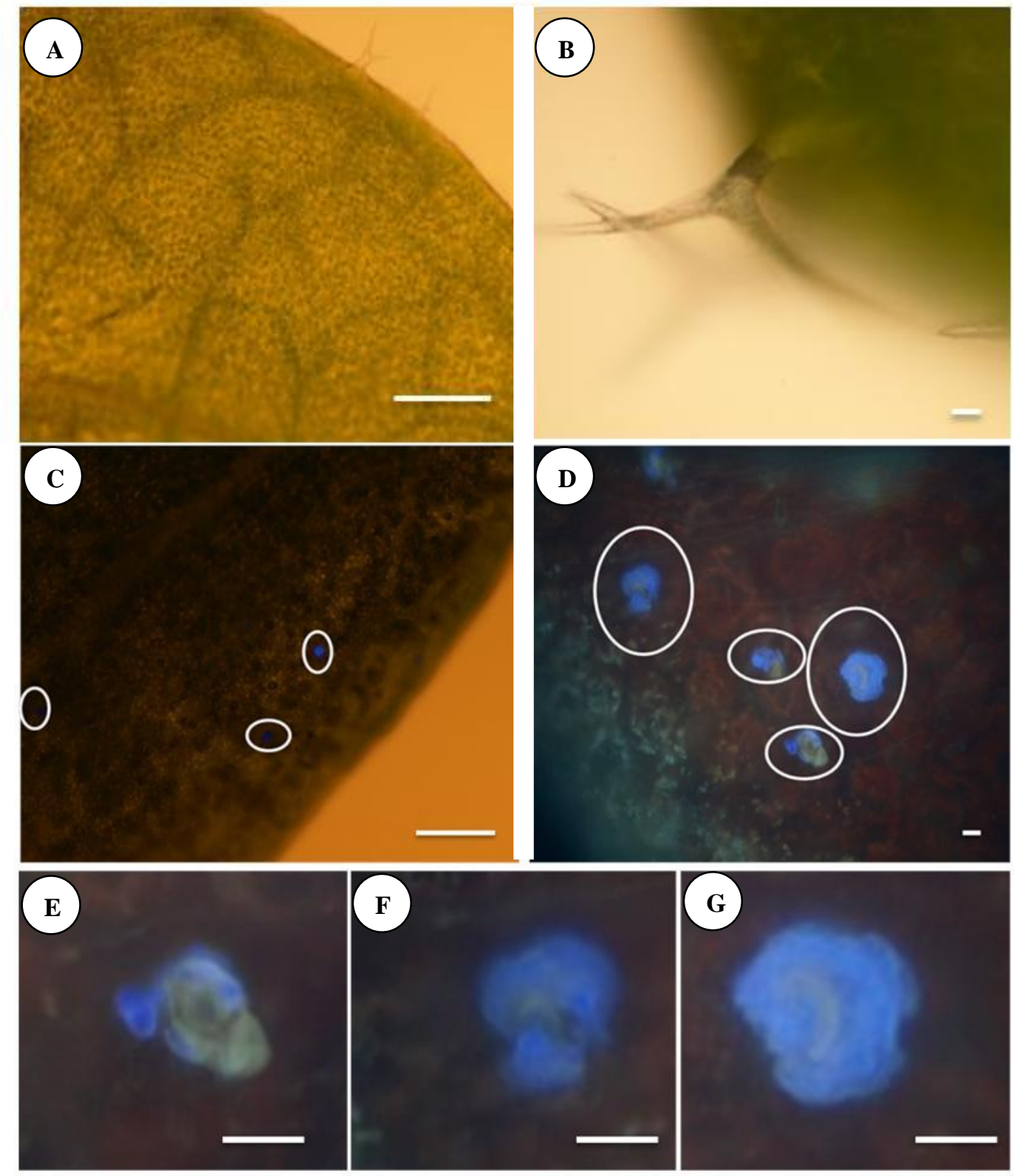

